\title{
Consumption of plant extract supplement reduces platelet activating factor-induced platelet aggregation and increases platelet activating factor catabolism: a randomised, double-blind and placebo-controlled trial
}

\author{
Lamprini Gavriil, Maria Detopoulou, Filio Petsini, Smaragdi Antonopoulou and Elizabeth Fragopoulou* \\ Department of Nutrition and Dietetics, Harokopio University, 70 Eleftheriou Venizelou Avenue Kallithea, \\ 17671 Athens, Greece
}

(Submitted 11 December 2018 - Final revision received 18 January 2019 - Accepted 4 February 2019 - First published online 03 April 2019)

\section{Abstract}

Platelet-activating factor (PAF) is a potent mediator of inflammation that plays a crucial role in atherosclerosis. The purpose of this study was to evaluate the effect of a dietary supplement containing mainly plant extracts on PAF actions and metabolism in healthy volunteers. A doubleblind, placebo-controlled, 8 weeks' duration study was performed. Healthy volunteers were randomly allocated into the supplement or the placebo group and fifty-eight of them completed the study. The supplement contained plant extracts (Aloe gel, grape juice, Polygonum cuspidatum) and vitamins. The activities of PAF metabolic enzymes: the two isoforms of acetyl-CoA:lyso-PAF acetyltransferase, cytidine 5'diphospho-choline:1-alkyl-2-acetyl-sn-glycerol cholinephosphotransferase (PAF-cholinephosphotransferase) and platelet-activating factoracetylhydrolase (PAF-AH) in leucocytes and lipoprotein associated phospholipase- $\mathrm{A}_{2}$ in plasma were measured along with several markers of endothelial function. Platelet aggregation against PAF, ADP and thrombin receptor activating peptide was measured in human platelet-rich plasma by light transmission aggregometry. No difference was observed on soluble vascular cell adhesion molecule-1, sP-selectin and IL-6 levels at the beginning or during the study period between the two groups. Concerning PAF metabolism enzymes' activity, no difference was observed at baseline between the groups. PAF-AH activity was only increased in the supplement group at 4 and 8 weeks compared with baseline levels. In addition, supplement consumption led to lower platelet sensitivity against PAF and ADP compared with baseline levels. However, a trial effect was only observed when platelets were stimulated by PAF. In conclusion, supplementation with plant extracts and vitamins ameliorates platelet aggregation primarily against PAF and secondarily against ADP and affects PAF catabolism by enhancing PAFacetylhydrolase activity in healthy subjects.

Key words: Grape extract: Aloe vera: Thrombosis: Inflammation: Endothelial function

Atherosclerosis is the main pathophysiological mechanism of CVD, the most common cause of morbidity and mortality worldwide. Platelet-activating factor (PAF) is a potent lipid mediator of inflammation and platelet aggregation that participates in the initiation and prolongation of atherosclerosis ${ }^{(1)}$. PAF levels are balanced via its enzymatic biosynthesis by the remodelling and the de novo pathways and its catabolism (Fig. 1) ${ }^{(2)}$. Briefly, initiation of the remodelling pathway leads phospholipase $\mathrm{A}_{2}$ to generate lysoPAF which is then acetylated by acetyl-CoA:lyso-platelet-activating factor acetyltransferases (Lyso-PAF AT) to form PAF. Two isoforms of Lyso-PAF AT are known, one of them is activated under inflammatory conditions, while the other one is $\mathrm{Ca}$ independent and does not participate in inflammatory processes ${ }^{(2,3)}$. The main enzyme of the de novo pathway is cytidine 5'-diphospho- choline:1-alkyl-2-acetyl-sn-glycerol cholinephosphotransferase (platelet-activating factor-cholinephosphotransferase (PAF-CPT)) which catalyses the synthesis of PAF from 1-O-alkyl-2-acetyl-glycerol $^{(4)}$. Concerning PAF catabolism, an intracellular plateletactivating factor-specific acetylhydrolase (PAF-AH) and its plasma isoform lipoprotein-associated phospholipase $\mathrm{A}_{2}\left(\mathrm{LpPLA}_{2}\right)$ are the key enzymes for the cleavage of the acetyl chain at the $s n-2$ position forming lyso-PAF ${ }^{(5)}$. PAF is also produced nonenzymatically along with oxidised phospholipids (oxPL) during LDL oxidation $^{(6)}$. The concomitant LpPLA 2 inactivation on oxidised LDL particles leads to augmentation of PAF and oxPL levels ${ }^{(6)}$.

PAF is a crucial component of inflammatory cell signalling and its actions are mediated through a specific $G$ protein-linked receptor $^{(7)}$. Overexpression of adhesion molecules along with

Abbreviations: $\mathrm{EC}_{50}$, concentration that induces $50 \%$ of maximum aggregation; LpPLA $\mathrm{A}_{2}$, lipoprotein-associated phospholipase $\mathrm{A}_{2}$; Lyso-PAF AT, lyso-plateletactivating factor acetyltransferase; Lyso-PAF ATC; lyso-platelet-activating factor acetyltransferase in the presence of Ca ${ }^{2+}$; Lyso-PAF ATE; lyso-platelet-activating factor acetyltransferase in the presence of EDTA; PAF, platelet-activating factor; PAF-AH, platelet-activating factor-acetylhydrolase; PAF-CPT, platelet-activating factor-cholinephosphotransferase; sVCAM, soluble vascular cell adhesion molecule; TRAP, thrombin receptor activating peptide.

* Corresponding author: E. Fragopoulou, fax +302109577050, email efragop@hua.gr 


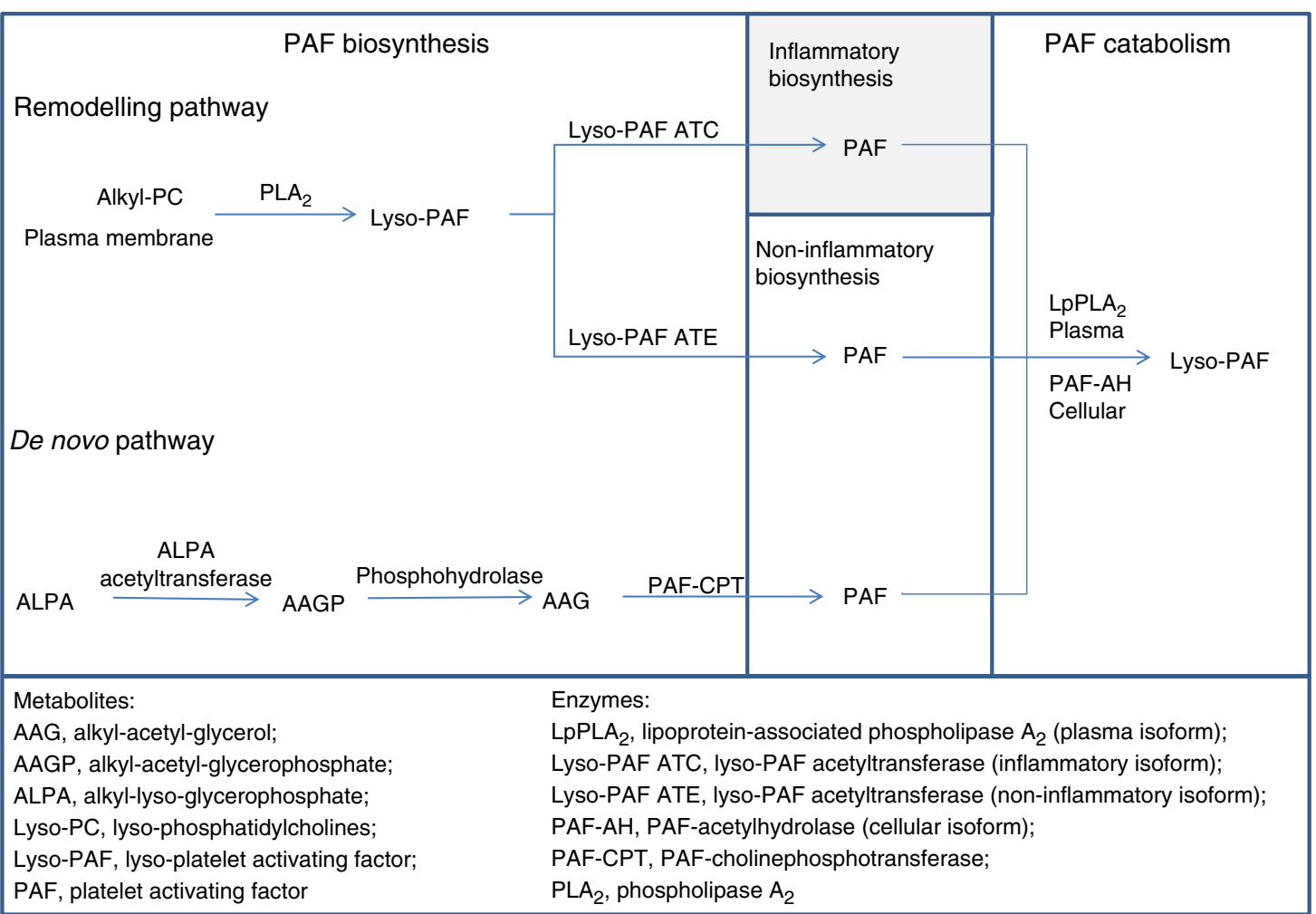

Fig. 1. Main enzymatic pathways of platelet-activating factor (PAF) metabolism. Metabolites: AAG, alkyl-acetyl-glycerol; AAGP, alkyl-acetyl-glycerophosphate; ALPA, alkyl-lyso-glycerophosphate; Lyso-PC, lyso-phosphatidylcholines; Lyso-PAF, lyso-platelet-activating factor; PAF. Enzymes: LpPLA ${ }_{2}$, lipoprotein-associated phospholipase $\mathrm{A}_{2}$ (plasma isoform); Lyso-PAF ATC, lyso-platelet-activating factor acetyltransferase in the presence of $\mathrm{Ca}^{2+}$ (inflammatory isoform); Lyso-PAF ATE, lyso-platelet-activating factor acetyltransferase in the presence of EDTA (non-inflammatory isoform); PAF-AH, platelet-activating factor-acetylhydrolase (cellular isoform); PAF-CPT, platelet-activating factor-cholinephosphotransferase; PLA $\mathrm{A}_{2}$, phospholipase $\mathrm{A}_{2}$.

PAF is required for recruitment and tight adhesion of platelets and leucocytes on endothelium. PAF regulates P-selectin translocation via both autocrine and intracrine signalling ${ }^{(8)}$ and mediates soluble vascular cell adhesion molecule 1 (sVCAM)induced secretion of leukotriene $\mathrm{C} 4$ in eosinophils ${ }^{(9)}$. Furthermore, PAF in coordination with other agonists like ADP and thrombin through their receptors promote signal transduction pathways, which raise intracellular concentration of $\mathrm{Ca}^{2+}$, alter platelets shape and lead to platelets aggregation ${ }^{(10)}$.

Several studies demonstrate the existence of food bioactive components that could interfere with endothelial function and platelet aggregation $^{(11)}$. Foods, such as tomatoes, vegetables, garlic, onions, olive oil and fish, have been shown in vitro to inhibit platelet aggregation via different mechanisms ${ }^{(11)}$. From this point of view, we previously identified compounds that inhibit PAFinduced platelet aggregation in vitro, namely, PAF inhibitors, in several foods, including virgin olive oil, fish and red/white wines $^{(12)}$. We have also reported that wine extracts and phenolic compounds inhibit Lyso-PAF AT and PAF-CPT activities in U937 monocytes under basal and inflammatory conditions ${ }^{(13,14)}$. In human studies, consumption of traditional Greek Mediterranean meals containing PAF inhibitors reduced platelet sensitivity against PAF in patients with type 2 diabetes mellitus and in healthy subjects ${ }^{(15)}$. Furthermore, the consumption of wines, which contained PAF inhibitors, along with a meal, ameliorates postprandial platelet sensitivity against $\mathrm{PAF}^{(16)}$ as well as the activities of Lyso-PAF AT and PAF-CPT in leucocytes of healthy $\operatorname{men}^{(17)}$. All the above support the idea that the consumption of Mediterranean foods that contain PAF inhibitors could have a protective effect on inflammation and thrombosis ${ }^{(18)}$. However, in our days the intense pace of life disrupts the pattern of balanced diet, and nutritional plant supplements are more often used, without always clinical evidences. Especially, as far as PAF actions and metabolism are concerned, limited data exist ${ }^{(19)}$.

The aim of the present study is to examine whether a combination of phytochemicals and vitamins with established anti-oxidant effect $^{(20)}$ may have an impact on PAF actions and metabolism. For this purpose, a double-blind, randomised and placebo-controlled clinical trial was undertaken in apparently healthy adults.

\section{Methods \\ Supplement}

The supplement Mind Master and a look-alike placebo were custom prepared and donated by LR Healthy and Beauty Systems Ltd. The supplement contained per dose of $80 \mathrm{ml}$, Aloe barbadensis miller gel (USA/Mexico 36\%), grape juice (32.5\%), Polygonum cuspidatum extract (which contains $10 \%$ resveratrol), green tea extract, $1 \cdot 1 \mathrm{mg}$ vitamin $\mathrm{B}_{1}, 2 \cdot 5 \mu \mathrm{g}$ vitamin $\mathrm{B}_{12}$, $12 \mathrm{mg}$ vitamin $\mathrm{E}$ ( $\alpha$-tocopherol equivalents), coenzyme Q10, $200 \mu \mathrm{g}$ folic acid, ascorbic acid, $27.5 \mu \mathrm{g}$ Se and $4.2 \mathrm{mg}$ Fe. The placebo comprised low concentration of $A$. barbadensis Miller gel (USA/Mexico 3.6\%), ascorbic acid and some excipients. 


\section{Study protocol}

This involves a double-blind, block randomised, parallel-arm, placebo-controlled study, and its duration was 8 weeks. A detailed description of the clinical study has already been reported ${ }^{(20)}$ and a brief description is presented in the online Supplementary material. A total of fifty-eight healthy volunteers completed the study. The study was conducted at the Metabolic Unit of the Department of Nutrition and Dietetics, Harokopio University, according to the guidelines laid down in the Declaration of Helsinki. Volunteers gave informed consent and the University Ethics Committee approved the experimental protocol. ClinicalTrials.gov Identifier for this study is NCT02837107.

\section{Blood sample collection}

Venous blood was collected after a $12 \mathrm{~h}$ fasting at the beginning of the study ( 0 weeks), at 4 weeks and at the end of the intervention ( 8 weeks) from the brachial vein of the volunteers. For the isolation of serum, venous blood samples were drawn into evacuated glass tubes and serum was collected after $45 \mathrm{~min}$ incubation at room temperature by centrifugation at $1500 \mathrm{~g}$ for $10 \mathrm{~min}$. For plasma isolation, EDTA vacutainers were used and blood was centrifuged immediately at $1500 \mathrm{~g}$ for $10 \mathrm{~min}$. For the isolation of leucocytes, $5 \mathrm{ml}$ of heparinised blood were obtained from each volunteer and leucocytes were isolated as previously described $^{(21)}$. Protein concentrations of all preparations were determined according to the Bradford method ${ }^{(22)}$, with the use of bovine serum albumin as protein standard. All biological samples were immediately aliquoted and stored at approximately $-80^{\circ} \mathrm{C}$.

\section{Haematological parameters and classic biochemical measurements}

Haematological parameters such as total leucocyte count, erythrocyte count, Hb level, haematocrit, erythrocyte indices such as mean corpuscular volume, mean corpuscular $\mathrm{Hb}$, mean corpuscular $\mathrm{Hb}$ concentration, erythrocyte distribution width, platelet count and mean platelet volume were determined by a Mindray Hematology Analyzer (BC 3000 plus). Enzymatic methods were used to define glucose, TAG, uric acid, total cholesterol, LDLcholesterol and HDL-cholesterol, as previously described ${ }^{(20)}$.

\section{Measurement of sP-selectin, soluble vascular cell adhesion} molecule-1 and IL-6

Sandwich ELISA kit were used for measurement of sP-selectin, sVCAM-1 (Duoset ELISA; R\&D Systems) and IL-6 (Quantikine HS ELISA; R\&D Systems). The intra-assay CV was $<10 \%$ for sVCAM/sP-selectin and $<7 \%$ for IL-6. The inter-assay CV was $<12 \%$ for sVCAM/sP-selectin and $<9.8 \%$ for IL- 6 .

\section{Ex vivo human platelet-rich plasma aggregation}

Blood was centrifuged at $170 \mathrm{~g}$ for $15 \mathrm{~min}$ to collect the supernatant platelet-rich plasma (PRP). Platelet-poor plasma (PPP) was obtained by recentrifugation of the pellet at a higher force. Platelet count of PRP was adjusted to 300 000/ml with PPP. Samples were incubated at $37^{\circ} \mathrm{C}$, with a stirring rate of $1000 \mathrm{rpm}$. Chronolog Aggregometer (Model 440Vs) was used for determining aggregation responses based on light transmittance method against various concentrations of PAF and ADP as well as against $2 \mu \mathrm{M}$ of thrombin receptor activating peptide (TRAP). For PAF and ADP, the maximum reversible or the least not reversible aggregation was estimated to evaluate the $100 \%$ aggregation. The plot of percentage aggregation (ranging from 20 to $80 \%$ ) $v$. different concentrations of agonist is linear. Based on this curve, $\mathrm{EC}_{50}$ value meaning concentration of PAF or ADP that induces $50 \%$ of maximum aggregation was calculated. In the case of TRAP, the percentage change in platelet aggregation (against $2 \mu \mathrm{M}$ of TRAP) $v$. baseline was calculated.

\section{Assay of lyso-platelet-activating factor acetyltransferase activity in leucocyte homogenate}

Two isoforms of Lyso-PAF AT were measured, the one is inducible and activated by inflammatory stimulation and the other is constitutively expressed. Isolated leucocyte homogenates, $15 \mu \mathrm{g}$ of total protein, were incubated for $10 \mathrm{~min}$ at $37^{\circ} \mathrm{C}$ with $4 \mathrm{nmol}$ of lyso-PAF and $40 \mathrm{nmol}$ of acetyl-CoA. Final reaction volume of $200 \mu \mathrm{l}$ was obtained by adding $50 \mathrm{~mm}$ Tris$\mathrm{HCl}$ buffer ( $\mathrm{pH} \mathrm{7.4)} \mathrm{containing} 0.25 \mathrm{mg} / \mathrm{ml}$ of bovine serum albumin $^{(23)}$. In the case of inducible Lyso-PAF AT, the assay was performed in the presence of $\mathrm{CaCl}_{2} 2.8 \mathrm{~mm}$ (Lyso-PAF ATC); and in the case of the constitutively Lyso-PAF AT, the assay was performed in the presence of EDTA $1.4 \mathrm{~mm}$ (Lyso-PAF ATE). Cold chloroform:methanol ( $2 \%$ acetic acid) was added for stopping the reaction. All assays were performed in duplicate.

\section{Assay of platelet-activating factor- cholinephosphotransferase activity in leucocyte homogenate}

In all, $15 \mu \mathrm{g}$ of isolated leucocyte homogenate protein was incubated at $37^{\circ} \mathrm{C}$ for $5 \mathrm{~min}$ with $100 \mathrm{~mm}$ Tris- $\mathrm{HCl}(\mathrm{pH} 8.0)$, $15 \mathrm{~mm}$ dithiothreitol, $0.5 \mathrm{~mm}$ EDTA, $20 \mathrm{~mm} \mathrm{MgCl}_{2}, 1 \mathrm{mg} / \mathrm{ml}$ of bovine serum albumin, $100 \mu \mathrm{m}$ of cytidine 5'-diphospho-choline and $100 \mu \mathrm{m}$ of $1-O-h e x a d e c y l-2$-acetyl-sn-glycerol in total reaction volume of $200 \mu \mathrm{l}$. Cold chloroform:methanol (2\% acetic acid) was added for stopping the reaction. All assays were performed in duplicate.

\section{Extraction and quantification of platelet-activating factor}

The levels of assay produced PAF were extracted by the acid Bligh-Dyer method ${ }^{(24)}$ and determined with liquid chromatography (LC)-MS. The enzymatic activity was expressed as specific activity pmol PAF/mg per min.

Extracted samples were inserted on Hypersil GOLD ${ }^{\mathrm{TM}}(5 \mu \mathrm{m}$, $150 \times 4.6 \mathrm{~mm}$; Thermo Scientific) for the analysis of assay product (PAF). The mobile phase contained $98 \%$ methanol LC-MS, $2 \% 1 \mathrm{~mm}$ aqueous ammonium acetate and the flow rate was $0 \cdot 1 \mathrm{ml} / \mathrm{min}$. MS analysis was performed using an Exactive ${ }^{\mathrm{TM}}$ Plus Orbitrap Mass Spectrometer (Thermo Scientific) with an electrospray ionisation source. Quantification was performed using 
the transition $m / z 524.37$ at retention peak time of $10 \mathrm{~min}$. A calibration curve, with range 1.6-24 pmol PAF, was routinely performed every two batches and a control PAF sample was included in each batch. Inter-day and intra-day precision was 15.9 and $11.8 \%$. Mass spectra were processed using the Xcalibur 4.0 (Thermo Scientific) software.

\section{Measurement of platelet-activating factor-acetylhydrolase activity in leucocyte homogenate and lipoprotein- associated phospholipase $A_{2}$ activity in serum}

Determination of PAF-AH activity was done in $30 \mu \mathrm{g}$ leucocyte homogenate protein based on the trichloroacetic acid precipitation method using $\left[{ }^{3} \mathrm{H}\right]$ PAF as a substrate ${ }^{(21)}$. Leucocyte homogenate was incubated with $4 \mathrm{nmol}$ of $\left[{ }^{3} \mathrm{H}\right] \mathrm{PAF}(20 \mathrm{~Bq} / \mathrm{nmol}), 100 \mathrm{~mm}$ Tris-HCl buffer ( $\mathrm{pH} 7.2)$ plus $1 \mathrm{~mm}$ ethylene glycol-bis(2aminoethylether)-N,N, $\mathrm{N}^{\prime}, \mathrm{N}^{\prime}$-tetraacetic acid (EGTA) for $15 \mathrm{~min}$ at $37^{\circ} \mathrm{C}$. Final reaction volume was $200 \mu \mathrm{l}$ and the reaction was stopped by adding cold trichloroacetic acid (10\% final concentration). Afterwards, samples were incubated in ice bath for $30 \mathrm{~min}$ and then were centrifuged at $15000 \mathrm{~g}$ for $2 \mathrm{~min}$. Liquid scintillation counter was used for the measurement of $\left[{ }^{3} \mathrm{H}\right]$ acetate which was released into the aqueous phase. All assays were performed in duplicate. The enzyme activity was expressed as specific activity $\mathrm{pmol} / \mathrm{mg}$ per min.

Serum LPPLA $_{2}$ activity was measured by a commercial kit using 2-thio PAF as a substrate (Cayman Chemical). The intraassay CV was $<4 \%$ and the inter-assay CV was $<10 \%$. All assays were performed in duplicate. The enzyme activity was expressed as specific activity $\mathrm{nmol} / \mathrm{min}$ per $\mathrm{ml}$.

\section{In vitro platelet aggregation in plasma rich in platelets}

The in vitro effect of supplement and its plant extracts (Aloe, grape skin, grape seed, extract that contain resveratrol) on platelet aggregation against PAF, ADP and TRAP was determined on PRP from healthy volunteers; $0 \%$ inhibition was considered as platelet aggregation without the addition of the examined sample. Plot of percentage inhibition (ranging from 20 to $80 \%$ ) $v$. different concentrations of the examined sample is linear, and it was used to calculate the concentration of the sample that induced $50 \%$ inhibition against each agonist. This value was defined as the $\mathrm{IC}_{50}$, namely, inhibitory concentration producing $50 \%$ inhibition.

\section{Statistical analysis}

Statistical analysis was done using SPSS 18 (SPSS Inc.) software. The primary outcome of the present study was a significant reduction in platelet aggregation, while the secondary outcome was a significant alteration of PAF metabolic enzyme activity. Considering the primary outcome, statistical power analysis revealed that nineteen participants in each arm was adequate to achieve statistical power equal to $95 \%$ at $5 \%$ significance level of two-sided hypotheses that evaluated $1 \mathrm{SD}$ differences based on $\mathrm{EC}_{50}$ values of platelet aggregation. The Kolmogorov-Smirnov criterion was used for testing normality and mean values and standard deviations are used for the presentation of normally distributed continuous variables, and medians and quartiles (25th-75th percentiles) for skewed variables. Comparisons of the baseline characteristics of our population are based on the independent-samples $t$ test for normally distributed variables, and the Mann-Whitney test for skewed variables. Furthermore, in skewed variables, the supplement and placebo groups at 4 and 8 weeks were compared by the MannWhitney test to illuminate a potential trial effect, while Friedman's two-way ANOVA by ranks was performed for testing the time effect within each trial. The Wilcoxon test for paired samples was also performed for testing the time effect within each trial. Repeatedmeasures ANOVA was applied for normally distributed variables for examining the trial effect, time effect and time $\times$ trial effect. Comparison between different biomarkers is based on Pearson. The significance level for $P$ values is $5 \%$.

\section{Results}

Biochemical markers, lifestyle characteristics and haematological parameters

Biochemical markers and lifestyle characteristics of volunteers have been previously reported ${ }^{(20)}$. Briefly, baseline anthropometric and biochemical markers of the study population did not differ between the two groups. No difference was observed at the levels of glucose, total cholesterol, HDL-cholesterol, LDLcholesterol, TAG and uric acid between groups at 4 weeks or at 8 weeks of the intervention (online Supplementary Table S1) ${ }^{(20)}$. Haematological parameters of volunteers at baseline and during the intervention are presented in Table 1. No significant changes were detected between the two groups.

\section{Platelet-activating factor enzymes activities, adhesion molecules and IL-6 at baseline}

To evaluate PAF metabolism, the activities of the biosynthetic enzymes, namely, PAF-CPT and the two isoforms of Lyso-PAF AT, namely, Lyso-PAF ATE (in the presence of EDTA) and Lyso-PAF ATC (in the presence of $\mathrm{Ca}^{2+}$ ) as well as of the catabolic ones, namely, LPPLA 2 and PAF-AH, were measured. PAF metabolic enzyme activities did not differ between the two examined groups at baseline (Table 2). The activities of both isoforms of Lyso-PAF AT, Lyso-PAF ATE and Lyso-PAF ATC, were positively correlated with PAF-CPT ( $r 0.608, P<0.001, r 0.346, P=0.01$, respectively) and with each other $(r 0.625, P<0 \cdot 001)$. The activity of LpPLA $_{2}$ was negatively correlated with the activity of Lyso-PAF ATC $(r-$ $0.404, P=0.003)$, while a trend of correlation was observed with the activity of Lyso-PAF ATE $(r-0.237, P=0.09)$. When the above correlations were adjusted for age, BMI, LDL (in the case of $\mathrm{LpPLA}_{2}$ ) and sex, the correlations remained significant and also the one between LpPLA $_{2}$ and Lyso-PAF ATE $(r-0.309, P=0.03)$ became significant and a trend of positive correlation was observed between LpPLA 2 and PAF-AH $(r$ 0.283, $P=0 \cdot 06)$.

No differences were observed in adhesion molecules sPselectin and sVCAM-1 levels or in IL-6 levels at the initiation of the study between the placebo and supplement groups (Table 2). Baseline levels of sP-selectin were positively correlated with the activities of $\mathrm{LpPLA}_{2}(r 0 \cdot 337, P=0 \cdot 01)$, PAF-CPT $(r$ $0.342, P=0 \cdot 01)$ and Lyso-PAF ATE $(r 0 \cdot 246, P=0 \cdot 07)$. Baseline levels of sVCAM-1 were negatively correlated with the activity 
Table 1. Levels of basic haematological markers before the intervention and during the intervention* (Mean values and standard deviations)

\begin{tabular}{|c|c|c|c|c|c|c|c|c|c|}
\hline \multirow[b]{2}{*}{ Time period (weeks) } & \multicolumn{2}{|c|}{0} & \multicolumn{2}{|c|}{4} & \multicolumn{2}{|c|}{8} & \multirow[b]{2}{*}{$P_{\text {trial }}$} & \multirow[b]{2}{*}{$P_{\text {time }}$} & \multirow[b]{2}{*}{$P_{\text {trial }} \times P_{\text {time }}$} \\
\hline & Mean & SD & Mean & SD & Mean & SD & & & \\
\hline \multicolumn{10}{|l|}{ Leucocytes $\left(10^{3} / \mu \mathrm{l}\right)$} \\
\hline Placebo & 5.75 & 1.44 & 5.72 & 1.41 & 5.47 & $1 \cdot 18$ & \multirow[t]{3}{*}{0.02} & \multirow[t]{2}{*}{0.8} & \multirow[t]{2}{*}{0.9} \\
\hline Supplement & $6 \cdot 24$ & 1.35 & 6.43 & 1.43 & 6.45 & 1.47 & & & \\
\hline \multicolumn{9}{|l|}{ LYMPH $\left(10^{3} / \mu \mathrm{l}\right)$} & \\
\hline Placebo & 1.84 & 0.37 & 1.82 & 0.51 & 1.82 & 0.45 & \multirow[t]{2}{*}{0.08} & \multirow[t]{2}{*}{0.4} & \multirow[t]{2}{*}{0.6} \\
\hline Supplement & $2 \cdot 10$ & 0.64 & 2.02 & 0.53 & $2 \cdot 10$ & 0.51 & & & \\
\hline \multicolumn{10}{|l|}{$\operatorname{MID}\left(10^{3} / \mu \mathrm{l}\right)$} \\
\hline Placebo & 0.42 & 0.11 & 0.40 & 0.14 & 0.43 & 0.17 & \multirow[t]{2}{*}{0.1} & \multirow[t]{2}{*}{0.4} & \multirow[t]{2}{*}{0.5} \\
\hline Supplement & 0.46 & 0.133 & 0.51 & 0.16 & 0.47 & 0.12 & & & \\
\hline \multicolumn{10}{|l|}{ GRAN $\left(10^{3} / \mu \mathrm{l}\right)$} \\
\hline Placebo & 3.51 & 1.23 & 3.50 & 1.06 & 3.25 & 0.85 & \multirow[t]{2}{*}{0.06} & \multirow[t]{2}{*}{0.8} & 0.8 \\
\hline Supplement & 3.71 & 1.00 & 3.89 & 1.03 & 3.90 & 1.22 & & & \\
\hline $\mathrm{Hb}(\mathrm{g} / \mathrm{l})$ & & & & & & & & & \\
\hline Placebo & 146 & $27 \cdot 2$ & 155 & $20 \cdot 2$ & 153 & $19 \cdot 4$ & 1.0 & 0.1 & 0.3 \\
\hline Supplement & 151 & $13 \cdot 4$ & 155 & $17 \cdot 7$ & 152 & 18.5 & & & \\
\hline Erythrocytes $\left(10^{6} / \mu l\right)$ & & & & & & & & & \\
\hline Placebo & 4.42 & 1.37 & 4.64 & 0.53 & 4.59 & 0.49 & 0.4 & 0.3 & 0.5 \\
\hline Supplement & 4.54 & 1.30 & 4.77 & 0.44 & 4.81 & 0.44 & & & \\
\hline HCT (\%) & & & & & & & & & \\
\hline Placebo & 39.71 & 4.81 & 38.81 & 4.48 & 38.72 & 4.49 & 0.6 & 0.002 & 0.9 \\
\hline Supplement & $40 \cdot 46$ & 3.81 & 39.79 & 4.38 & 39.69 & 3.63 & & & \\
\hline MCV (fl) & & & & & & & & & \\
\hline Placebo & 86.33 & 5.09 & 85.80 & 4.84 & $86 \cdot 61$ & 3.40 & 0.01 & 0.6 & 0.2 \\
\hline Supplement & 81.88 & 9.97 & 83.48 & 6.65 & 83.34 & 6.38 & & & \\
\hline $\mathrm{MCH}(p g)$ & & & & & & & & & \\
\hline Placebo & 31.59 & 2.87 & 33.43 & $2 \cdot 80$ & $33 \cdot 20$ & 2.84 & 0.07 & 0.01 & 0.5 \\
\hline Supplement & 31.24 & 2.92 & 32.54 & 3.48 & 31.66 & $4 \cdot 16$ & & & \\
\hline $\mathrm{MCHC}(\mathrm{g} / \mathrm{l})$ & & & & & & & & & \\
\hline Placebo & $366 \cdot 7$ & 29.7 & $390 \cdot 3$ & $24 \cdot 1$ & 383.4 & 24.6 & 0.3 & 0.4 & 0.3 \\
\hline Supplement & $483 \cdot 3$ & $56 \cdot 4$ & $390 \cdot 2$ & 24.9 & $379 \cdot 3$ & 31.8 & & & \\
\hline RDW (\%) & & & & & & & & & \\
\hline Placebo & 12.92 & 0.81 & 16.93 & 18.81 & $12 \cdot 88$ & 0.60 & 0.5 & 0.2 & 0.3 \\
\hline Supplement & 13.46 & 1.29 & 13.60 & 1.28 & 13.34 & $1 \cdot 16$ & & & \\
\hline $\operatorname{PLT}\left(10^{3} / \mu \mathrm{l}\right)$ & & & & & & & & & \\
\hline Placebo & 224.04 & $59 \cdot 13$ & 211.00 & 44.02 & $215 \cdot 88$ & $45 \cdot 40$ & 0.08 & 0.9 & 0.06 \\
\hline Supplement & 240.64 & 32.42 & 245.79 & 47.00 & 251.98 & 42.44 & & & \\
\hline MPV (fl) & & & & & & & & & \\
\hline Placebo & $7 \cdot 74$ & 0.63 & 7.79 & 0.63 & 7.79 & 0.64 & 0.3 & 0.5 & 0.5 \\
\hline Supplement & 7.89 & 0.50 & 7.75 & 0.64 & 7.79 & 0.58 & & & \\
\hline РCT (\%) & & & & & & & & & \\
\hline Placebo & 0.17 & 0.38 & 0.16 & 0.31 & 0.17 & 0.33 & 0.1 & 0.9 & 0.3 \\
\hline Supplement & 0.19 & 0.02 & 0.20 & 0.03 & 0.19 & 0.03 & & & \\
\hline
\end{tabular}

LYMPH, Iymphocytes; MID, monocytes, eosinophils, basophils, blasts and other precursor white cells; GRAN, granulocytes; HCT, haematocrit; MCV, mean corpuscular volume; MCH, mean corpuscular Hb; MCHC, mean corpuscular Hb

concentration; RDW, erythrocyte distribution width; PLT, platelets; MPV, mean platelet volume; PCT, plateletcrit.
* Data are presented as means and standard deviations for normally distributed variables. Repeated-measures ANOVA was used for comparisons. 
Table 2. Levels of adhesion molecules, IL-6 and platelet-activating factor (PAF) enzyme activity before the intervention* (Mean values and standard deviations; medians and 25th-75th percentiles)

\begin{tabular}{|c|c|c|c|c|c|}
\hline & \multicolumn{2}{|c|}{ Placebo } & \multicolumn{2}{|c|}{ Supplement } & \multirow[b]{2}{*}{$P$} \\
\hline & Mean & SD & Mean & SD & \\
\hline sP-selectin (ng/ml) & \multirow{3}{*}{\multicolumn{2}{|c|}{$\begin{array}{c}38 \cdot 5 \\
27 \cdot 3-65 \cdot 8\end{array}$}} & & & 0.9 \\
\hline Median & & & \multirow{2}{*}{\multicolumn{2}{|c|}{$\begin{array}{c}36 \cdot 2 \\
31.9-54.4\end{array}$}} & \\
\hline 25th-75th percentiles & & & & & \\
\hline sVCAM-1 (ng/ml) & & & \multicolumn{2}{|c|}{$31.9-54 \cdot 4$} & 0.8 \\
\hline Median & \multicolumn{2}{|c|}{$\begin{array}{c}418 \cdot 3 \\
300 \cdot 7-503 \cdot 4\end{array}$} & \multirow{2}{*}{\multicolumn{2}{|c|}{$\begin{array}{c}407 \cdot 7 \\
303 \cdot 6-457 \cdot 8\end{array}$}} & \\
\hline 25th-75th percentiles & \multirow{2}{*}{\multicolumn{2}{|c|}{$300 \cdot 7-503 \cdot 4$}} & & & \\
\hline IL-6 (pg/ml) & & & & & 0.2 \\
\hline Median & \multirow{2}{*}{\multicolumn{2}{|c|}{$\begin{array}{c}0.596 \\
0.331-0.842\end{array}$}} & \multirow{2}{*}{\multicolumn{2}{|c|}{$\begin{array}{c}0.725 \\
0.460-1.02\end{array}$}} & \\
\hline 25th-75th percentiles & & & & & \\
\hline PAF-CPT (pmol/mg per min) & 134.4 & $43 \cdot 1$ & $136 \cdot 0$ & $31 \cdot 7$ & 0.9 \\
\hline Lyso-PAF ATC (pmol/mg per min) & 42.9 & $18 \cdot 3$ & $47 \cdot 36$ & 38.5 & 0.6 \\
\hline Lyso-PAF ATE (pmol/mg per min) & $56 \cdot 7$ & $16 \cdot 6$ & $53 \cdot 2$ & $20 \cdot 2$ & 0.5 \\
\hline PAF-AH (pmol/mg per min) & $150 \cdot 4$ & 71.5 & $155 \cdot 2$ & 84.6 & 0.8 \\
\hline $\operatorname{LpPLA}_{2}(\mu \mathrm{mol} / \mathrm{min}$ per $\mathrm{ml})$ & 24.7 & $6 \cdot 6$ & $26 \cdot 6$ & $7 \cdot 6$ & 0.3 \\
\hline
\end{tabular}

Table 3. Effect of intervention on the levels of adhesion molecules and IL-6 (Medians and lower-upper quartiles (25th-75th percentiles) for skewed variables)

\begin{tabular}{|c|c|c|c|c|c|}
\hline \multirow[b]{2}{*}{ Percentage of baseline levels } & \multicolumn{2}{|c|}{4 weeks } & \multicolumn{2}{|c|}{8 weeks } & \multirow[b]{2}{*}{$P_{\text {time }}{ }^{\star}$} \\
\hline & Median & 25th-75th & Median & 25th-75th & \\
\hline \multicolumn{6}{|l|}{ sP-selectin (ng/ml) } \\
\hline Placebo & 101.6 & $86 \cdot 1-124 \cdot 0$ & 104.5 & $75 \cdot 6-127 \cdot 1$ & 0.8 \\
\hline Supplement & $98 \cdot 3 \dagger$ & $88 \cdot 5-111 \cdot 0$ & $97 \cdot 1 \dagger$ & $80 \cdot 3-120 \cdot 5$ & 0.97 \\
\hline \multicolumn{6}{|l|}{ sVCAM-1 (ng/ml) } \\
\hline Placebo & $98 \cdot 8$ & $88 \cdot 8-103.9$ & $97 \cdot 6$ & $90 \cdot 6-106 \cdot 9$ & 0.7 \\
\hline Supplement & $100 \cdot 0 \dagger$ & $91 \cdot 4-108 \cdot 1$ & 99.9† & $89 \cdot 9-106 \cdot 5$ & 0.5 \\
\hline \multicolumn{6}{|l|}{ IL-6 (pg/ml) } \\
\hline Placebo & $120 \cdot 1$ & $91 \cdot 0-139 \cdot 3$ & $132 \cdot 7$ & $70 \cdot 7-186 \cdot 6$ & 0.2 \\
\hline Supplement & $120 \cdot 2 \dagger$ & $71 \cdot 8-196 \cdot 0$ & $106 \cdot 6 \dagger$ & $72 \cdot 9-152 \cdot 7$ & 0.3 \\
\hline
\end{tabular}

sVCAM, soluble vascular cell adhesion molecule.

${ }^{*} P_{\text {time }}$ : Friedman's two-way ANOVA by ranks was used for the estimation of the time effect within the placebo or supplement group. $\dagger P_{\text {trial }}$ : the Mann-Whitney $U$ independent test was used for comparison of the supplement $v$. placebo group at 4 or 8 weeks.

of LpPLA $_{2}(r-0 \cdot 266, P=0 \cdot 05)$ and the levels of IL-6 were negatively correlated with Lyso-PAF ATC $(r-0 \cdot 293, P=0 \cdot 03)$. After adjustment for age, sex and LDL-cholesterol (in the case of $\mathrm{LpPLA}_{2}$ ), the above correlations were not retained with the exception of the one between sP-selectin and PAF-CPT.

\section{Effect of intervention on endothelial cell adhesion} molecules and IL-6

No significant time or trial effect was observed concerning the levels of sVCAM-1, sP-selectin and IL-6 at 4 and 8 weeks of supplementation (Table 3).

\section{Effect of intervention on the activity of platelet-activating factor metabolic enzymes}

A significant time effect was observed on PAF-AH activity and a trend on Lyso-PAF ATC activity (Table 4). Specifically, PAF-AH activity was increased at 4 and 8 weeks in the supplement group compared with baseline $\left(P_{0-4}=0 \cdot 008, P_{0-8}=0 \cdot 01\right)$ and a trend for increase was also detected in Lyso-PAF ATC activity in the placebo group compared with baseline $\left(P_{0-4}=0 \cdot 07\right)$.

\section{Effect of intervention on ex vivo platelet aggregation against platelet-activating factor, ADP and thrombin receptor activating peptide}

A significant time effect was revealed only in the supplement group, which was agonist dependent. In specific, a significant time effect was observed on platelet aggregation against PAF $(P=0.001)$, a trend for time effect on platelet aggregation against ADP $(P=0.06)$, while no time effect was observed on platelet aggregation against TRAP (Table 5). Compared with baseline, the $\mathrm{EC}_{50}$ values against $\mathrm{PAF}$ in the supplement group were significantly increased at $4(P<0.001)$ and 8 weeks $(P=0.01)$, indicating lower platelet sensitivity. Compared with baseline levels, the 
Table 4. Effect of intervention on platelet-activating factor (PAF) metabolism enzyme activity* (Mean values and standard deviations for normally distributed variables)

\begin{tabular}{|c|c|c|c|c|c|c|c|}
\hline \multirow[b]{2}{*}{ Percentage of baseline levels } & \multicolumn{2}{|c|}{4 weeks } & \multicolumn{2}{|c|}{8 weeks } & \multirow[b]{2}{*}{$P_{\text {trial }}$} & \multirow[b]{2}{*}{$P_{\text {time }}$} & \multirow[b]{2}{*}{$P_{\text {trial }} \times P_{\text {time }}$} \\
\hline & Mean & SD & Mean & SD & & & \\
\hline \multicolumn{8}{|l|}{ PAF-CPT (pmol/mg per min) } \\
\hline Placebo & 98.4 & $18 \cdot 1$ & $98 \cdot 3$ & $22 \cdot 9$ & \multirow[t]{2}{*}{0.7} & \multirow[t]{2}{*}{0.9} & \multirow[t]{2}{*}{0.9} \\
\hline Supplement & $101 \cdot 2$ & $20 \cdot 2$ & $98 \cdot 8$ & 19.5 & & & \\
\hline \multicolumn{8}{|c|}{ Lyso-PAF ATC (pmol/mg per min) } \\
\hline Placebo & $116 \cdot 4$ & 43.8 & $113 \cdot 7$ & 44.5 & \multirow{2}{*}{0.9} & \multirow{2}{*}{0.06} & \multirow[t]{2}{*}{0.9} \\
\hline Supplement & $116 \cdot 4$ & 71.25 & 111.7 & $58 \cdot 9$ & & & \\
\hline \multicolumn{8}{|c|}{ Lyso-PAF ATE (pmol/mg per min) } \\
\hline Placebo & $100 \cdot 9$ & $21 \cdot 8$ & $103 \cdot 8$ & 33.9 & \multirow[t]{2}{*}{0.5} & \multirow[t]{2}{*}{0.3} & \multirow[t]{2}{*}{$0 \cdot 6$} \\
\hline Supplement & $108 \cdot 0$ & 29.8 & $106 \cdot 6$ & $28 \cdot 3$ & & & \\
\hline \multicolumn{8}{|l|}{$\operatorname{LpPLA}_{2}(\mu \mathrm{mol} / \mathrm{min}$ per ml) } \\
\hline Placebo & $97 \cdot 1$ & $12 \cdot 1$ & $101 \cdot 0$ & $13 \cdot 6$ & \multirow[t]{2}{*}{0.7} & \multirow[t]{2}{*}{0.2} & \multirow[t]{2}{*}{0.7} \\
\hline Supplement & $99 \cdot 2$ & $8 \cdot 7$ & $100 \cdot 8$ & $12 \cdot 2$ & & & \\
\hline \multicolumn{8}{|l|}{ PAF-AH (pmol/mg per min) } \\
\hline Placebo & $115 \cdot 5$ & $66 \cdot 09$ & $112 \cdot 6$ & $52 \cdot 0$ & \multirow[t]{2}{*}{0.2} & \multirow[t]{2}{*}{0.007} & \multirow[t]{2}{*}{0.4} \\
\hline Supplement & $131 \cdot 6$ & $61 \cdot 1$ & 134.8 & 74.0 & & & \\
\hline
\end{tabular}

PAF-CPT, platelet-activating factor-cholinephosphotransferase; Lyso-PAF ATC, lyso-platelet-activating factor acetyltransferase in presence of Ca ${ }^{2+}$; Lyso-PAF ATE; lyso-plateletactivating factor acetyltransferase in the presence of EDTA; LPPLA $A_{2}$, lipoprotein-associated phospholipase $A_{2} ;$ PAF-AH, platelet-activating factor-acetylhydrolase.

${ }^{*}$ A repeated-measures ANOVA was used for the comparisons.

Table 5. Effect of intervention on platelet aggregation against platelet-activating factor (PAF), ADP and thrombin receptor activating peptide (TRAP) (Medians and lower-upper quartiles (25th-75th percentiles) for skewed variables)

\begin{tabular}{|c|c|c|c|c|c|}
\hline \multirow[b]{2}{*}{ Percentage of baseline levels } & \multicolumn{2}{|c|}{4 weeks } & \multicolumn{2}{|c|}{8 weeks } & \multirow[b]{2}{*}{$P_{\text {time }} \dagger$} \\
\hline & Median & 25th-75th & Median & 25th-75th & \\
\hline \multicolumn{6}{|l|}{$\mathrm{EC}_{50}$ PAF $(\mu \mathrm{M})$} \\
\hline Placebo & $100 \cdot 0$ & $61 \cdot 2-111 \cdot 6$ & $81 \cdot 0$ & $50 \cdot 7-119 \cdot 4$ & $0 \cdot 6$ \\
\hline Supplement & $168 \cdot 8^{*} \ddagger$ & $104 \cdot 6-242 \cdot 9$ & $181 \cdot 4^{*} \ddagger$ & $98 \cdot 1-442 \cdot 2$ & 0.001 \\
\hline \multicolumn{6}{|l|}{$\mathrm{EC}_{50} \mathrm{ADP}(\mathrm{mM})$} \\
\hline Placebo & $100 \cdot 0$ & $44 \cdot 2-137 \cdot 0$ & $106 \cdot 0$ & $76 \cdot 9-163 \cdot 7$ & $0 \cdot 2$ \\
\hline Supplement & $130 \cdot 5 \ddagger$ & $62 \cdot 6-236 \cdot 6$ & 144.9‡ & $75 \cdot 5-215 \cdot 9$ & 0.06 \\
\hline \multicolumn{6}{|c|}{ Amplitude change against $2 \mu \mathrm{M}$ TRAP } \\
\hline Placebo & 98.0 & $55-111$ & 99.0 & $69-109$ & 0.7 \\
\hline Supplement & $96 \cdot 0 \ddagger$ & $78 \cdot 25-107 \cdot 8$ & 104.0‡ & $76-114$ & 0.4 \\
\hline
\end{tabular}

$\mathrm{EC}_{50}$, concentration that induces $50 \%$ of maximum aggregation.

* $P<0.05$.

$\dagger P_{\text {time }}$ : Friedman's two-way ANOVA by ranks was used for the estimation of the time effect in the placebo or supplement trial.

$\ddagger P_{\text {trial }}$ : the Mann-Whitney $U$ independent test was used for comparison of supplement $v$. placebo at 4 or 8 weeks.

Table 6. Effect of total supplement and its individual extract components on in vitro platelet aggregation*

\begin{tabular}{lccc}
\hline & $\mathrm{IC}_{50}$ PAF & $\mathrm{IC}_{50}$ ADP & IC $_{50}$ TRAP \\
\hline Supplement $(\mu \mathrm{I})$ & 28.4 & 26.3 & 26.5 \\
Aloe gel extract $(\mathrm{mg})$ & $\mathrm{ND}$ & $\mathrm{ND}$ & $\mathrm{ND}$ \\
Grape skin extract $(\mathrm{mg})$ & 0.083 & 0.77 & 1.44 \\
Grape seed extract $(\mathrm{mg})$ & 0.035 & 0.029 & 0.028 \\
Resveratrol extract $(\mathrm{mg})$ & 0.38 & 0.44 & 0.20 \\
\hline $\mathrm{IC}_{50}$, inhibitory concentration producing $50 \%$ inhibition; PAF, platelet-activating factor; TRAP, thrombin receptor activating peptide; ND, \\
not detected.
\end{tabular}

$\mathrm{EC}_{50}$ values against $\mathrm{ADP}$ in the supplement group were also increased at $4(P=0.03)$ and 8 weeks $(P=0.003$, respectively).

A significant trial effect at 4 and 8 weeks of supplementation was only observed against PAF-induced aggregation. In specific, $\mathrm{EC}_{50}$ values against PAF were higher at both $4(P=0 \cdot 02)$ and 8 weeks $(P=0 \cdot 02) v$. placebo group (Table 5$)$.

\section{Effect of total supplement and its main individual components on in vitro platelet aggregation}

The in vitro anti-thrombotic ability of the supplement's extract components against platelet aggregation induced by PAF, ADP and TRAP in healthy volunteers' PRP was also performed (Table 6). The 
in vitro results revealed that the supplement inhibited platelet aggregation against all agonists. The examination of each extract separately showed that grape juice (seed and skin extract) and especially grape skin exerted the most potent anti-platelet activity against PAF. In contrast, Aloe vera gel exhibited very slight antiplatelet activity that never reached $50 \%$ inhibition regardless of the agonist.

\section{Discussion}

Atherosclerosis is a multifactorial pathological situation which includes prolonged inflammation, endothelial dysfunction and platelet aggregation. PAF is a potent inflammatory mediator that is implicated in platelet aggregation and degranulation, leucocyte-platelet interactions, endothelium permeability and subsequently in the infiltration of leucocytes into the sub-endothelial matrix $^{(1)}$. The objective of this study was to evaluate the effect of 8-week supplementation mainly with plant extracts along with vitamins on PAF actions and metabolism, inflammatory and endothelial function biomarkers.

Previous data support the idea that PAF production is implicated in the adhesion of leucocytes to endothelium ${ }^{(25)}$ and probably PAF acts complementary to P-selectin to activate insideout signalling of b2 integrins on neurophiles ${ }^{(26)}$. As was described, the volunteers had a medium adherence to the Mediterranean diet and were overweight ${ }^{(20)}$. At baseline, the levels of the soluble adhesion molecules (sVACM, sP-selectin) and IL-6 were in the physiological range for healthy subjects ${ }^{(27,28)}$. As far as PAF metabolism is concerned, the activities of PAF-CPT and LpPLA were similar with the previous ones reported for the Greek population $^{(29)}$, while no data exist for the activities of Lyso-PAF ATC and Lyso-PAF ATE that were strongly and positively correlated with the activity of PAF-CPT of the de novo pathway, indicating a parallel regulation of the two pathways. This result is in accordance with a previous publication in the general Greek population where total acetyltransferase activity (Lyso-PAF AT) was correlated with PAF-CPT ${ }^{(29)}$. The activity of the catabolic enzyme LPPLA 2 was also negatively correlated with the activity of Lyso-PAF ATC and Lyso-PAF ATE. In the present study, biosynthetic enzyme PAF-CPT was positively correlated with sPselectin independently of age, BMI and sex, supporting the idea that PAF acts complementary to P-selectin.

The platelet aggregation assay, which is the most common bioassay evaluating PAF activity ${ }^{(30)}$, showed that the $\mathrm{EC}_{50}$ values against PAF-induced platelet aggregation at baseline levels were positively correlated to the corresponding ones of ADP, supporting a parallel sensitivity of platelets against these two agonists. The $\mathrm{EC}_{50}$ values against $\mathrm{ADP}$-induced platelet aggregation (higher $\mathrm{EC}_{50}$ value means lower sensitivity) were negatively correlated with sVCAM levels, indicating a parallel activation of platelets and endothelial cells.

The present study used a supplement that contains natural plant extracts mainly $A$. vera gel (36\%) and grape juice (32.5\%) but also $P$. cuspidatum that contains $10 \%$ resveratrol along with vitamins. The results revealed that 4 - and 8 -week supplementation did not affect the levels of sP-selectin, sVCAM-1 and IL-6 in healthy subjects. Concerning A. vera, no previous reports exist comparing the above results. In vitro data reported that grape seed proanthocyanidin extract inhibits VCAM-1 expression in human endothelial cells stimulated by TNF- $\alpha^{(31)}$ and reduces the expression of P-selectin and VCAM-1 in rats ${ }^{(32)}$. However, in vivo reports concerning the effect of natural products consumption on VCAM levels are in agreement with the results of the present study since 8 weeks' daily consumption of resveratrol $(250 \mathrm{mg})^{(33)}$ and 4 weeks' consumption of green tea ${ }^{\text {(28) }}$ did not alter sVCAM-1 levels in healthy volunteers. Concerning sP-selectin, in contrast with the present study, it was reported that consumption of anthocyanin capsules reduced P-selectin expression measured by flow cytometer in a sedentary population ${ }^{(27)}$ and 4 weeks consumption of green tea decreased sP-selectin levels in male smokers ${ }^{(28)}$. It should be mentioned that in the first study different methodology was used $^{(27)}$, and in the second one ${ }^{(28)}$ baseline values of P-selectin were double compared with the values of the present study. Focusing in clinical trials with vitamin supplementation, much higher dosages than the ones presented in this study were used, without always have a beneficial effect on the levels of the adhesion molecules in healthy populations ${ }^{(34-36)}$

As far as PAF metabolic enzymes are concerned, the supplementation did not alter the activity of its biosynthetic enzymes in the leucocyte homogenate of volunteers' activity of plasma LpPLA 2 . However, the activity of intracellular PAF-AH in volunteers' leucocytes homogenate was increased in the supplement group at 4 and 8 weeks compared with the baseline levels, indicating a reduction in PAF levels. Unfortunately, comparisons with other reports are difficult, since most studies are restricted to cell cultures. In vitro data support that resveratrol and wine extracts inhibit Lyso-PAF AT and PAF-CPT activities in U-937 monocytes under basal and inflammatory conditions $^{(14)}$ and flavonoids inhibit Lyso-PAF AT activity in endothelial cells ${ }^{(37,38)}$. Also, wine consumption parallel with a meal has been reported to reduce PAF biosynthetic enzymes in postprandial state ${ }^{(17)}$. Concerning PAF catabolic enzymes, tea extract is reported to inhibit in vitro $\mathrm{LpPLA}_{2}^{(39)}$ and in vivo in the metabolic syndrome subjects after supplementation with red yeast rice olive ${ }^{(40)}$. No data exist concerning vitamins in vivo effects on PAF metabolism.

Activated platelets are an important contributor of atherothrombosis development. Anti-platelet drugs have been reported to have side effects and increase resistant in target populations; therefore, the use of natural extracts is a potential alternative $^{(11)}$. The supplementation in the present study resulted in reduction of platelet sensitivity against PAF (higher $\mathrm{EC}_{50}$ values) at 4 and 8 weeks, compared with the placebo group and reduction of platelet sensitivity against both PAF and ADP at 4 and 8 weeks compared with the baseline values. In contrast, no results were observed with regard to the sensitivity against TRAP that activates platelets thought thrombin receptors; however, due to the limited blood volume collected, no $\mathrm{EC}_{50}$ values were calculated in the case of TRAP. In vitro data support that grape juice extract, green tea extract and resveratrol reduce platelet aggregation ${ }^{(41,42)}$, while no data exist concerning the effect of $A$. vera on platelet aggregation. In this context, it has been shown that resveratrol is capable of reducing platelet aggregation against $\mathrm{PAF}^{(43)}$. Also, 4 weeks' consumption of grape juice with resveratrol inhibited platelet 
aggregation against thrombin in healthy subjects ${ }^{(44)}$ and anthocyanin capsules supplementation reduced ADP-induced whole blood platelet aggregation in a sedentary population ${ }^{(27)}$, although the consumption of a grape seed extract rich in low-molecularweight polyphenolic compounds did not alter platelet aggregation in subjects with hypertension ${ }^{(45)}$. Furthermore, the consumption of wines, which contain PAF inhibitors, along with a meal ameliorates postprandial platelet sensitivity against PAF in healthy men ${ }^{(16)}$. The observed effect on platelet aggregation could be attributed to the synergistic effect of all extracts along with vitamins with some extracts playing more crucial role since our in vitro experiments revealed that grape skin and seed extracts along with resveratrol but not Aloe gel inhibit platelet aggregation against PAF, ADP and TRAP in a dose-dependent manner. However, we should consider the fact that extracts' micro-constituents could undergo modifications through their absorption and metabolism and the observed effect may be attributed to the initial compounds or to their metabolites ${ }^{(46)}$. Concerning the effect of vitamins, it is reported that vitamin $\mathrm{E}$ in dosages of $200-600 \mathrm{mg} / \mathrm{d}$ has no significant effect on platelet aggregation in vivo, although in vitro results supported this idea $^{(47)}$. In contrast, 5 months' consumption of supplement that combined $600 \mathrm{mg}$ ascorbic acid, $300 \mathrm{mg} \alpha$-tocopherol, $27 \mathrm{mg}$ carotene and $75 \mathrm{mg}$ Se reduced aggregation of platelets against ADP in men $^{(48)}$. It should be mentioned that the dosages in the above studies were much higher, so comparison with the present study is difficult.

The limitations of the present study are that our population is healthy with medium adherence to Mediterranean diet; thus, our results are difficult to generalise in patients or in healthy subjects with balanced diet. Compliance of participants' to the study protocol was estimated by the assessment of the supplement's volume that has not been consumed and not by methods that measured vitamins or other nutrients. The study design does not allow conclusions regarding the effect of each component of the supplement on the observed results.

In conclusion, the consumption of a supplement that contains mainly plant extracts along with vitamins reduces platelet sensitivity against PAF and ADP in healthy subjects. No other effect was observed on inflammatory or endothelial function markers with the exception of intracellular PAF catabolic enzyme, namely, PAF acetylhydrolase, where an increase was detected.

\section{Acknowledgements}

The authors are grateful to the participants of this study. Also the authors would like to thank Antigoni Tsiafitsa for her technical assistance in blood sample collection and Chrysa Argyrou and Ioanni Malagari for their contribution in handling of biological samples.

The study was partly funded from LR Healthy and Beauty. The founder was not involved in the study design, the collection, the analysis, the data interpretation, the writing of the manuscript as well as in the decision to submit the article for publication.

E. F. designed and supervised the implementation of the study; L. G. contributed to the handling of biological samples and measured endothelial/inflammation markers, platelet aggregation and PAF enzyme activity; M. D. and F. P. contributed to the measurement of PAF enzyme activity; S. A. critically revised the manuscript.

The authors declare that there are no conflicts of interest.

\section{References}

1. Demopoulos CA, Karantonis HC \& Antonopoulou S (2003) Platelet activating factor - a molecular link between atherosclerosis theories. Eur J Lipid Sci Technol 105, 705-716.

2. Snyder F (1995) Platelet-activating factor and its analogs: metabolic pathways and related intracellular processes. Biochim Biophys Acta 1254, 231-249.

3. Harayama T, Shindou H, Ogasawara R, et al. (2008) Identification of a novel noninflammatory biosynthetic pathway of platelet-activating factor. J Biol Chem 283, 11097-11106.

4. Snyder F (1997) CDP-choline:alkylacetylglycerol cholinephosphotransferase catalyzes the final step in the de novo synthesis of platelet-activating factor. Biochim Biophys Acta 1348, 111-116.

5. Stafforini DM (2009) Biology of platelet-activating factor acetylhydrolase (PAF-AH, lipoprotein associated phospholipase A2). Cardiovasc Drugs Ther 23, 73-83.

6. Liapikos TA, Antonopoulou S, Karabina SP, et al. (1994) Platelet-activating factor formation during oxidative modification of low-density lipoprotein when PAF-acetylhydrolase has been inactivated. Biochim Biophys Acta 1212, 353-360.

7. Zimmerman GA, McIntyre TM, Prescott SM, et al. (2002) The platelet-activating factor signaling system and its regulators in syndromes of inflammation and thrombosis. Crit Care Med 30, S294-S301.

8. Rollin S, Lemieux C, Maliba R, et al. (2004) VEGF-mediated endothelial P-selectin translocation: role of VEGF receptors and endogenous PAF synthesis. Blood 103, 3789-3797.

9. Tsuruta R, Cobb RR, Mastrangelo M, et al. (1999) Soluble vascular cell adhesion molecule (VCAM)-Fc fusion protein induces leukotriene $\mathrm{C} 4$ secretion in platelet-activating factorstimulated eosinophils. J Leukocyte Biol 65, 71-79.

10. Savage B, Cattaneo M \& Ruggeri ZM (2001) Mechanisms of platelet aggregation. Curr Opin Hematol 8, 270-276.

11. Vilahur G \& Badimon L (2013) Antiplatelet properties of natural products. Vasc Pharmacol 59, 67-75.

12. Nomikos T, Fragopoulou E \& Antonopoulou S (2007) Food ingredients and lipid mediators. Curr Nutr Food Sci 3, 255-276.

13. Xanthopoulou MN, Asimakopoulos D, Antonopoulou S, et al. (2014) Effect of Robola and Cabernet Sauvignon extracts on platelet activating factor enzymes activity on U937 cells. Food Chem 165, 50-59.

14. Vlachogianni IC, Fragopoulou E, Stamatakis GM, et al. (2015) Platelet activating factor (PAF) biosynthesis is inhibited by phenolic compounds in U-937 cells under inflammatory conditions. Prostaglandins Other Lipid Mediat 121, 176-183.

15. Antonopoulou S, Fragopoulou E, Karantonis HC, et al. (2006) Effect of traditional Greek Mediterranean meals on platelet aggregation in normal subjects and in patients with type 2 diabetes mellitus. J Med Food 9, 356-362.

16. Xanthopoulou MN, Kalathara K, Melachroinou S, et al. (2017) Wine consumption reduced postprandial platelet sensitivity against platelet activating factor in healthy men. Eur J Nutr $\mathbf{5 6}$, $1485-1492$

17. Argyrou C, Vlachogianni I, Stamatakis G, et al. (2017) Postprandial effects of wine consumption on platelet activating 
factor metabolic enzymes. Prostaglandins Other Lipid Mediat 130, 23-29.

18. Nomikos T, Fragopoulou E, Antonopoulou S, et al. (2018) Mediterranean diet and platelet-activating factor: a systematic review. Clin Biochem 60, 1-10.

19. Cha TW, Kim M, Kim M, et al. (2016) Blood pressure-lowering effect of Korean red ginseng associated with decreased circulating Lp-PLA ${ }_{2}$ activity and lysophosphatidylcholines and increased dihydrobiopterin level in prehypertensive subjects. Hypertens Res 39, 449-456.

20. Fragopoulou E, Gavriil L, Argyrou C, et al. (2018) Suppression of DNA/RNA and protein oxidation by dietary supplement which contains plant extracts and vitamins: a randomized, double-blind, placebo-controlled trial. Lipids Health Dis 17, 187.

21. Detopoulou P, Nomikos T, Fragopoulou E, et al. (2009) Platelet activating factor (PAF) and activity of its biosynthetic and catabolic enzymes in blood and leukocytes of male patients with newly diagnosed heart failure. Clin Biochem 42, 44-49.

22. Bradford MM (1976) A rapid and sensitive method for the quantitation of microgram quantities of protein utilizing the principle of protein-dye binding. Anal Biochem 72, 248-254.

23. Fragopoulou E, Iatrou C \& Demopoulos CA (2005) Characterization of acetyl-CoA: lyso-PAF acetyltransferase of human mesangial cells. Mediators Inflamm 2005, 263-272.

24. Bligh EG \& Dyer WJ (1959) A rapid method of total lipid extraction and purification. Can J Biochem Physiol 37, 911-917.

25. Zimmerman GA, McIntyre TM, Mehra M, et al. (1990) Endothelial cell-associated platelet-activating factor: a novel mechanism for signaling intercellular adhesion. J Cell Biol 110, 529-540.

26. Zimmerman GA, McIntyre TM \& Prescott SM (1996) Adhesion and signaling in vascular cell-cell interactions. J Clin Invest 98, 1699-1702.

27. Thompson K, Hosking H, Pederick W, et al. (2017) The effect of anthocyanin supplementation in modulating platelet function in sedentary population: a randomised, double-blind, placebo-controlled, cross-over trial. Br J Nutr 118, 368-374.

28. Lee W, Min WK, Chun S, et al. (2005) Long-term effects of green tea ingestion on atherosclerotic biological markers in smokers. Clin Biochem 38, 84-87.

29. Detopoulou P, Nomikos T, Fragopoulou E, et al. (2012) PAF and its metabolic enzymes in healthy volunteers: interrelations and correlations with basic characteristics. Prostaglandins Other Lipid Mediat 97, 43-49.

30. Bossant MJ, Ninio E, Delautier D, et al. (1990) Bioassay of PAF-acether by rabbit platelet aggregation. Methods Enzymol 187, 125-130.

31. Sen CK \& Bagchi D (2001) Regulation of inducible adhesion molecule expression in human endothelial cells by grape seed proanthocyanidin extract. Mol Cell Biochem 216, 1-7.

32. Zhang Y, Shi H, Wang W, et al. (2011) Antithrombotic effect of grape seed proanthocyanidins extract in a rat model of deep vein thrombosis. J Cardiovasc Surg 53, 743-753.

33. Gliemann L, Schmidt JF, Olesen J, et al. (2013) Resveratrol blunts the positive effects of exercise training on cardiovascular health in aged men. $J$ Physiol 591, 5047-5059.
34. van Dijk SC, Enneman AW, Swart KM, et al. (2016) Effect of vitamin $\mathrm{B}_{12}$ and folic acid supplementation on biomarkers of endothelial function and inflammation among elderly individuals with hyperhomocysteinemia. Vasc Med 21, 91-98.

35. Woollard KJ, Rayment SJ, Bevan R, et al. (2006) Alphatocopherol supplementation does not affect monocyte endothelial adhesion or C-reactive protein levels but reduces soluble vascular adhesion molecule- 1 in the plasma of healthy subjects. Redox Rep 11, 214-222.

36. Koh KK, Blum A, Hathaway L, et al. (1999) Vascular effects of estrogen and vitamin $\mathrm{E}$ therapies in postmenopausal women. Circulation 100, 1851-1857.

37. Yanoshita R, Chang HW, Son KH, et al. (1996) Inhibition of lysoPAF acetyltransferase activity by flavonoids. Inflamm Res 45, 546-549.

38. Balestrieri ML, Castaldo D, Balestrieri C, et al. (2003) Modulation by flavonoids of PAF and related phospholipids in endothelial cells during oxidative stress. J Lipid Res 44, 380-387.

39. Zeng L, Yan J, Luo L, et al. (2015) Effects of Pu-erh tea aqueous extract (PTAE) on blood lipid metabolism enzymes. Food Funct 6, 2008-2016.

40. Hermans N, Van der Auwera A, Breynaert A, et al. (2017) A red yeast rice-olive extract supplement reduces biomarkers of oxidative stress, OxLDL and Lp-PLA 2 , in subjects with metabolic syndrome: a randomised, double-blind, placebocontrolled trial. Trials 18, 302.

41. Borriello A, Cucciolla V, Della Ragione F, et al. (2010) Dietary polyphenols: focus on resveratrol, a promising agent in the prevention of cardiovascular diseases and control of glucose homeostasis. Nutr Metab Cardiovasc Dis 20, 618-625.

42. Vitseva O, Varghese S, Chakrabarti S, et al. (2005) Grape seed and skin extracts inhibit platelet function and release of reactive oxygen intermediates. J Cardiovasc Pharmacol $\mathbf{4 6}$, $445-451$.

43. Fragopoulou E, Nomikos T, Antonopoulou S, et al. (2000) Separation of biologically active lipids from red wine. J Agric Food Chem 48, 1234-1238.

44. Pace-Asciak CR, Rounova O, Hahn SE, et al. (1996) Wines and grape juices as modulators of platelet aggregation in healthy human subjects. Clin Chim Acta 246, 163-182.

45. Ras RT, Zock PL, Zebregs YE, et al. (2013) Effect of polyphenol-rich grape seed extract on ambulatory blood pressure in subjects with pre- and stage I hypertension. $\mathrm{Br} \mathrm{J}$ Nutr 110, 2234-2241.

46. Velderrain-Rodríguez GR, Palafox-Carlos H, Wall-Medrano A, et al. (2014) Phenolic compounds: their journey after intake. Food Funct 5, 189-197.

47. Steiner M (1991) Influence of vitamin $E$ on platelet function in humans. J Am Coll Nutr 10, 466-473.

48. Salonen JT, Salonen R, Seppanen K, et al. (1991) Effects of antioxidant supplementation on platelet function: a randomized pair-matched, placebo-controlled, double-blind trial in men with low antioxidant status. Am J Clin Nutr 53, 1222-1229. 